\title{
MECHANICAL EVALUATION OF POLYETHERETHERKETONE COMPARED WITH ZIRCONIA AS A DENTAL IMPLANT MATERIAL
}

\author{
Youssef M. Kassem¹ BDS, Ahmad M. Alshimy² PhD, Sonia M. El-Shabrawy ${ }^{3} P h D$.
}

\begin{abstract}
INTRODUCTION: Dental implants are currently one of the main pillars of restorative dentistry. Titanium and its alloys were and still are the gold standard for dental implant materials. However, Titanium is not a perfect material and has many drawbacks thus the search for a more ideal material is ongoing. Zirconia and Polyetheretherketone are two viable alternatives to titanium as dental implant materials. They show different mechanical behavior invitro and invivo, so they are investigated and compared to each other.

OBJECTIVES: Evaluate and compare the different material properties of Polyetheretherketone and yttrium-stabilized tetragonal polycrystalline zirconia when used as dental implant material.

MATERIALS AND METHODS: Microbars of zirconia and Polyetheretherketone were prepared using precision cutter and low speed micro motor under water cooling and used to assess the following properties for the two materials: 1) Vickers Microhardness 2) Flexural strength before and after cyclic loading

RESULTS: There was a highly significant difference between hardness of zirconia and Polyetheretherketone. There was also a highly significant difference between flexural strength of zirconia and Polyetheretherketone (both before and after cyclic loading). There was significant decrease in flexural strength of zirconia after cyclic loading. No significant difference was found for Polyetheretherketone after cyclic loading.

CONCLUSIONS: Polyetheretherketone is a promising alternative to titanium and zirconium as a dental implant material.

KEYWORDS: Dental implant, Flexural strength, Hardness, PEEK, Zirconia.

1- Demonstrator of dental biomaterials, Dental biomaterials department, Faculty of Dentistry, Alexandria University, Alexandria, Egypt.

2- Professor and head of the department of removable prosthodontics, Removable prosthodontics department, Faculty of Dentistry, Alexandria University, Alexandria, Egypt.

3- Professor and head of the department of dental biomaterials, Dental biomaterials department, Faculty of Dentistry, Alexandria University, Alexandria, Egypt.
\end{abstract}

Corresponding author:

E-mail: y_k_1989@hotmail.com

\section{INTRODUCTION}

Missing teeth and their supporting oral tissues are one of the major concerns in modern dentistry. Traditional management included replacement using fixed or removable partial dentures, which despite their wide use had several drawbacks. Dental implants offer a viable alternative. They offer an improved quality of life for most patients with tooth loss(1). The material chosen for endosseous implants has been and still is commercially pure titanium, introduced in 1969 by Branemark et al(2).

Although the use of titanium (Ti) and $\mathrm{Ti}$ alloys as the main material for dental implants is the gold standard (3), a range of problems were attributed to their use. Ti hypersensitivity was a potential problem(4). Another main issue is stress shielding which could occur due to the difference in elastic moduli between Ti implants and their surrounding bone, eventually leading to peri-implant bone $\operatorname{loss}(5)$.

Another disadvantage of $\mathrm{Ti}$ as a dental implant material is its dark grayish color and its lack of light transmission which occasionally appears through thin gingival biotype compromising the esthetic outcome of the treatment. This risk is greatly emphasized when replacing teeth in the esthetic zone and in patients with high smile line (6). Additionally, an increasing number of patients are demanding completely metal-free dental reconstructions (7).

To overcome Ti drawbacks ceramic implants were proposed as an alternative. Aluminum oxide implants were the first ceramic implants introduced 40 years ago (7).
However a frequent fracture incidence was reported impeding their wide use(8). Currently, zirconia is the material of choice for ceramic dental implants, offering adequate mechanical and physical properties to overcome the drawbacks of Ti implants(9).

Recently, yttrium-stabilized tetragonal polycrystalline zirconia (Y-TZP) dental implants were shown to promote osseointegration, produce an excellent soft tissue response, low plaque affinity, and can have a natural tooth-like color(10). However, the elastic modulus of Ti and zirconia were found to be $110 \mathrm{Gpa}$ and $210 \mathrm{Gpa}$, respectively, which are 5-14 times greater than that of compact bone (15 Gpa) (11). Minimizing marginal bone loss after years of functional bone loading is one of the main parameters in assessing long-term clinical success of dental implants(12).

Polyetheretherketone (PEEK) is another biocompatible material with an elastic modulus of $3.6 \mathrm{Gpa}$ (13). The modulus of elasticity of PEEK could be modified by adding carbon fibers to achieve a modulus of $18 \mathrm{Gpa}$ similar to that of cortical bone(14). PEEK is a high-performance thermoplastic polymer which over the past few decades has been extensively used in orthopedic applications and spinal implants since it was proposed as a suitable biomaterial in the 1980 s(15).

The PEEK-Optima is a composite mixture of polyetheretherketone and inert materials. It is currently being used in craniofacial surgery, spinal surgery and, orthopedics. PEEK-Optima is currently proposed as a material for dental implants due to its superior biological and mechanical properties. It possesses many other 
advantages including; its natural beige color, reduced magnetic resonance imaging artifacts, and radiolucency on $\mathrm{X}$-rays(16). The past decade has seen increasing interest in PEEK as an alternative to metal implants, because of its superior mechanical and biological properties (17).

\section{MATERIALS AND METHODS}

\section{A. Materials}

1. Yttrium-stabilized tetragonal polycrystalline zirconia (YTZP) (Ceramill Zolid Amman Girbach AG, Koblach Austria) available in the form of partially sintered CAD CAM discs.

2. Polyetheretherketon (PEEK) (PEEK OPTIMA Juvora Ltd, Lanchire, UK) available in the form of CAD CAM discs.

\section{B. Methods}

Total of eighty specimens were prepared according to the international specifications for each test (40 specimens for hardness, 40 for flexural strength). The specimens were divided into two groups according to the materials used in this study as following:

Group I (control group):

Forty specimens of Y-TZP (20 for hardness, 20 for flexural strength).

Group II (study group):

Forty specimens of PEEK (20 for hardness, 20 for flexural strength).

\section{Specimen preparation:}

Group I (control group):

- Partially sintered discs were cut into twenty microbars of dimensions $(1.5 * 20 * 1 \mathrm{~mm})$ for flexural strength according to ASTM D790 (18).

- Twenty microbars of dimensions $(5 * 25 * 1.5 \mathrm{~mm})$ were cut for microhardness (19).

- All specimens were cut into their specific dimensions using microtome precision cutter (Micracut 151 Metcon Instruments Inc.) under water cooling.

- All zirconia microbars were completely sintered using high temperature furnace according to manufactures instructions;(20) (Heat Rate600 $\quad\left({ }^{\circ} \mathrm{C} / \mathrm{h}\right)$, Holding Temperature and Time 900; $0.5 \mathrm{~h}$; , further with $200^{\circ} \mathrm{C} / \mathrm{h}$, Final Temperature $1450\left({ }^{\circ} \mathrm{C}\right)$, Holding Time 2 (h), Cooling Rate $\left.600\left({ }^{\circ} \mathrm{C} / \mathrm{h}\right)\right)$.

\section{Group II (study group):}

- PEEK discs were cut into 40 microbars of dimensions (5*25*1.5 mm) according to ASTM C1161 (21) (20 for flexural strength, 20 for hardness (22)).

- All microbars were cut into their specific dimensions using microtome precision cutter under water cooling.

2. Vickers microhardness test $(19,22)$

- Twenty specimens of each group were used to assess the hardness by using Vickers microhardness tester (Instron Wolpert HMV-2000) using a diamond indenter, in the form of a right pyramid with a square base and an angle of 136 degrees between opposite faces subjected to a load of (1 kg for zirconia and 500g for PEEK). The full load was applied for 15 seconds. The two diagonals of the indentation after removal of the load were measured using an optical microscope and their average was calculated. The area of the sloping surface of the indentation was calculated.

- The Vickers hardness was the quotient by dividing the load by the square area of indentation:

$\mathrm{HV}=1.8544 \mathrm{~F} / \mathrm{d} \wedge 2$
Where:

- HV = the Vickers hardness value,

- $\mathrm{F}=$ load in $\mathrm{kg}$,

- $\mathrm{d}^{2}=$ arithmetic mean of the two diagonal in $\mathrm{mm}$.

3. Flexural strength test

- Both group I and II are divided into two equal subgroups of 10 (Subgroup A of each group was tested immediately while subgroup B was subjected to cyclic loading prior to testing).

Cyclic loading (23):

- Ten specimens of each group were artificially aged in cyclic loading chewing simulator. The cyclic loading machine used performed 1 stroke per second with uniform load of $1 \mathrm{Kg}$.

- In order to simulate 1 year of clinical service; 240 thousand cycles were performed for each specimen.

Flexural strength test $(18,21)$

- Three point bending test was performed to calculate the flexural strength of zirconium and PEEK microbars through stress-strain curve.

- Twenty specimens were used to conduct the test. Specimens were submitted to the flexural strength test in a universal testing machine (Comten 700 series, Comten Idustries, Inc.) at a crosshead speed of $0.5 \mathrm{~mm} / \mathrm{min}$ until fracture.

- The maximum fracture load (P, in Newton) of each specimen was recorded, and the flexural strength (FS), in $\mathrm{MPa}$, was calculated as follows:

Where: $\mathrm{FS}=3 \mathrm{PL} /(2 \mathrm{bd} \wedge 2)$

- P: Fracture load

- L: Distance between the supporting rollers

- b: Specimen width;

- d: Specimen thickness.

- While the elastic modulus (E), in GPa was calculated as follows:

Where:

$$
\mathrm{E}=(\mathrm{PL} \wedge 3) /(4 \mathrm{bhd} \wedge 3)
$$

- P: Fracture load

- L: Distance between the supporting rollers

- b: Specimen width;

- d: Specimen thickness.

- h: deflection corresponding to the load P

C. Statistical analysis

- Data were fed to the computer and analyzed using IBM SPSS software package version 20.0. Quantitative data were described using range (minimum and maximum), mean, standard deviation and median. Significance of the results was judged at the $5 \%$ level(24).

- The tests that were used were Student t- test and ANOVA with repeated measures

\section{RESULTS}

\section{Vickers microhardness test}

- All microbars from group I \& II were tested using Vickers microhardness tester .Fig (1), Table (1).

- The test showed statistically significant difference between hardness of zirconia (group I) (1250.6 \pm 82.32 $\mathrm{kg} / \mathrm{mm} 2$ ) and hardness of PEEK (group II) (31.55 \pm $2.67 \mathrm{~kg} / \mathrm{mm} 2)(\mathrm{t}=0.000)$. 


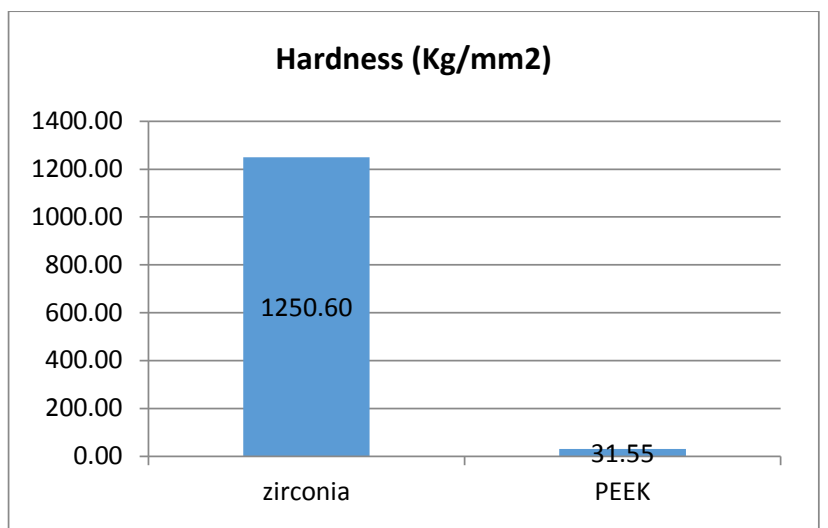

Figure (1): Bar chart showing the mean values of Vickers microhardness in zirconia (group I) Vs PEEK (group II).

Table (1): Showing the mean values of Vickers microhardness of zirconia (Group I) and compared to PEEK (Group II).

\begin{tabular}{||c|c|c||}
\hline $\begin{array}{c}\text { Vickers microhardness } \\
\left(\mathbf{k g} / \mathbf{m m}^{2}\right)\end{array}$ & Zirconia & PEEK \\
\hline Min. - Max. & $1114-1419$ & $28.2-37.5$ \\
Mean \pm SD. & $1250.6 \pm 82.32$ & $31.55 \pm 2.67$ \\
Median & 1285 & 30.4 \\
\hline t- value & \multicolumn{2}{|c|}{66.797} \\
\hline Sig. & & 0.000 \\
\hline
\end{tabular}

\section{Flexural strength test}

- During testing, all the zirconia microbars of group I showed minimal bending then broke into two pieces. In all the specimens the fracture line was located near the center of the specimens where the load was applied.

- All the fractured specimens could be reassembled and the line of fracture wasn't clearly seen.

- In group II all the PEEK microbars showed gradual bending till the maximum deflection capacity of the material without fracture.

- Statistical analysis showed statistically significant decrease in the flexural strength of zirconia after cyclic loading $\left(89.7 \pm 11.4 \mathrm{~N} / \mathrm{mm}^{2}\right)$ when compared to zirconia before cyclic loading $\left(135.1 \pm 23.5 \mathrm{~N} / \mathrm{mm}^{2}\right)(\mathrm{t}=0.000)$. Also analysis showed significant decrease in the elastic modulus of zirconia after cyclic loading $(149.59 \pm 19.1$ $\mathrm{GPa}$ ) when compared to zirconia before cyclic loading $(216.49 \pm 37.7 \mathrm{GPa})(\mathrm{t}=0.000)$.

- On the other hand PEEK showed no statistically significant difference in flexural strength after cyclic loading $\left(27.3 \pm 2.2 \mathrm{~N} / \mathrm{mm}^{2}\right)$ and before $(26.7 \pm 4.3$ $\left.\mathrm{N} / \mathrm{mm}^{2}\right)(\mathrm{t}=0.710)$. Also analysis showed no significant difference in the elastic modulus of PEEK after cyclic loading $(6.11 \pm 0.49 \mathrm{GPa})$ when compared to PEEK before cyclic loading $(5.94 \pm 0.96 \mathrm{GPa})(\mathrm{t}=0.650)$.

- Also there was a statistically significant difference between flexural strength of zirconia before (135.1 \pm 23.5 $\left.\mathrm{N} / \mathrm{mm}^{2}\right)$ and after $\left(89.7 \pm 11.4 \mathrm{~N} / \mathrm{mm}^{2}\right)$ cyclic loading when compared to that of PEEK $\left(26.7 \pm 4.3 \mathrm{~N} / \mathrm{mm}^{2}\right)$, $\left(26.7 \pm 4.3 \mathrm{~N} / \mathrm{mm}^{2}\right)(\mathrm{t}=0.000)$ Fig (2), Table (2). Also there was a statistically significant difference between elastic modulus of zirconia before (216.49 $\pm 37.7 \mathrm{GPa})$ and after (149.59 $\pm 19.1 \mathrm{GPa})$ cyclic loading when compared to that of PEEK (5.94 $\pm 0.96 \mathrm{GPa}),(6.11 \pm 0.49$ GPa) (t=0.000) Fig (3) Table (3).

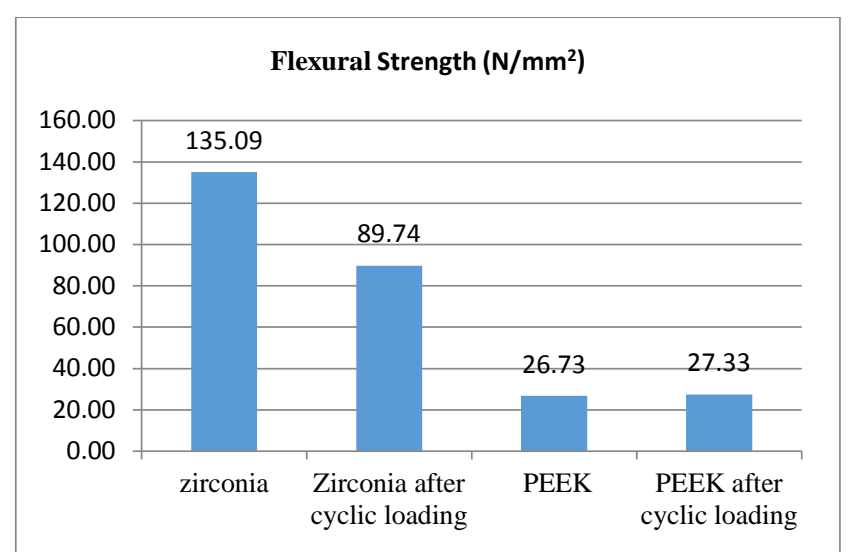

Figure (2): Bar chart showing the mean values of flexural strength of both zirconia and PEEK before and after cyclic loading

Table (2): Showing the mean values of flexural strength of the four test specimens

\begin{tabular}{|c|c|c|c|c|}
\hline $\begin{array}{c}\text { Flexural } \\
\text { strength } \\
\text { (N/mm }^{2} \text { ) }\end{array}$ & Zirconia & $\begin{array}{c}\text { Zirconia } \\
\text { after cyclic } \\
\text { loading }\end{array}$ & PEEK & $\begin{array}{c}\text { PEEK after } \\
\text { cyclic loading }\end{array}$ \\
\hline Min. - Max. & $\begin{array}{c}107.3- \\
168.3\end{array}$ & $71.1-100.1$ & $20.2-32.7$ & $24.2-30.3$ \\
Mean \pm SD. & $\begin{array}{c}135.1 \pm \\
23.5\end{array}$ & $89.7 \pm 11.4$ & $26.7 \pm 4.3$ & $27.3 \pm 2.2$ \\
Median & 135.5 & 96.8 & 27.1 & 26.7 \\
\hline
\end{tabular}

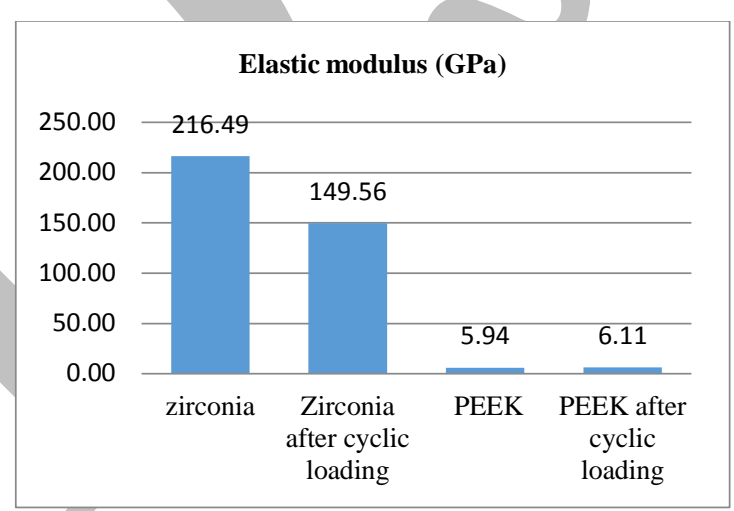

Figure (3): Bar chart showing the mean values of elastic modulus of both zirconia and PEEK before and after cyclic loading

Table (3): Showing the mean values of elastic modulus of the four test specimens

\begin{tabular}{|c|c|c|c|c||}
\hline $\begin{array}{c}\text { Elastic } \\
\text { modulus } \\
\text { (GPa) }\end{array}$ & Zirconia & $\begin{array}{c}\text { Zirconia } \\
\text { after cyclic } \\
\text { loading }\end{array}$ & PEEK & $\begin{array}{c}\text { PEEK after } \\
\text { cyclic loading }\end{array}$ \\
\hline Min. - Max. & $\begin{array}{c}171.9- \\
269.9\end{array}$ & $118.6-166.9$ & $4.5-7.3$ & $5.4-6.8$ \\
Mean \pm SD. & $\begin{array}{c}216.49 \pm \\
37.7\end{array}$ & $\begin{array}{c}149.59 \pm \\
19.1\end{array}$ & $5.94 \pm 0.96$ & $6.11 \pm 0.49$ \\
Median & 217.1 & 161.4 & 6.1 & 6.0 \\
\hline
\end{tabular}




\section{DISCUSSION}

Endosseous dental implants are a surgical device inserted surgically into the jaw bone to support a prosthodontic or orthodontic appliance (25). For decades $\mathrm{Ti}$ and its alloys have been the universal choice of implants material (26). However, Ti appeared to have a number of drawbacks. Firstly, esthetics posed a major side-effect for titanium as it tends to discolor the underlying gingiva of thin biotype (6).

Moreover, Ti has a modulus of elasticity much higher than that of "bone, this difference may cause alveolar bone resorption in a process known as "stress shielding "(16). Recent studies also reported cases of Ti allergy in patients receiving Ti dental implants (4). It is also becoming a trend among patients to request metal-free treatments (7).

Over the past few years multiple researches were focused on studying alternatives to Ti. Zirconia is an esthetic ceramic which was proposed as a possible replacement to Ti. Yttrium-stabilized tetragonal polycrystalline zirconia (Y-TZP) dental implants are currently the material of choice for dental implants. Researchers showed that they possess excellent mechanical and physical properties and could promote osseointegration (10). However, its modulus of elasticity is much higher than that of bone which might lead to bone loss due to stress shielding (11).

Recently, polymeric implant materials have been developed. PEEK is a tooth colored polymer, which has multiple medical and dental application (17). In medicine PEEK has been used in spinal surgery, fracture fixation devices, joint replacement and maxillofacial surgery(27). In dentistry PEEK has been used in the construction of CAD/CAM milled fixed crowns and bridges and removable dentures (28).

PEEK is currently tested as a dental implant material, this is mainly due to its natural beige color and its modulus of elasticity which is close to that of bone(16). However, the potential of PEEK to replace titanium as the material for dental implants is still debatable(25).

The main purpose of this study is to evaluate and compare Y-TZP and PEEK when used as an implant material. Two tests were performed for this purpose which are; Vickers microhardness, Flexural strength.

Surface microhardness is an important property for dental implant materials. The surface hardness is the resistance of a material to surface abrasion(29). Dental implants require different types of surface treatment to achieve adequate osseointegration(30). Knowledge of the surface hardness of different dental implant materials is essential to perform proper surface treatments.

For group I zirconia showed a significantly high hardness value of mean $1250.6 \pm 82.32 \mathrm{~kg} / \mathrm{mm} 2$.

The results of the current study are consistent with the findings of Pittayachawan et al (2007)(31). The results of their study testing Vickers microhardness were $1344 \pm 75$ $\mathrm{kg} / \mathrm{mm} 2$ for non polished zirconia and $1319 \pm 70 \mathrm{~kg} / \mathrm{mm} 2$ for polished zirconia. Similarly, Vagkopoulou et al (2009) (32) stated that the average Vickers microhardness value of Y-TZP was $1270 \mathrm{~kg} / \mathrm{mm} 2$

The results are also comparable to the findings of Ewais et al (2014)(19) . The authors measured Vickers microhardness for different types of Y-TZP with different surface treatments and found that the average microhardness value is $1346 \pm 11.2 \mathrm{~kg} / \mathrm{mm} 2$. Similarly Ramamoorthi et al (2015) (33) stated that the average microhardness of Y-TZP is $1200 \mathrm{~kg} / \mathrm{mm} 2$. Salihoglu Yener et al (2015)(29) reported the average microhardness value of the same zirconia used in our study and found the average was $1357 \pm 24 \mathrm{~kg} / \mathrm{mm} 2$.

For group II PEEK showed a relatively low hardness value of mean $31.55 \pm 2.67 \mathrm{~kg} / \mathrm{mm} 2$.

Goyal et al (2008)(34) conducted an experiment testing the microhardness for different high performance PEEK matrix composites. The results obtained in this study were in agreement with our results with the average microhardness value $34.9 \mathrm{~kg} / \mathrm{mm} 2$.Also Wang et al (2015)(35) measured the hardness value of different PEEK composites and found that the average Vickers microhardness value is 28.5 $\mathrm{kg} / \mathrm{mm} 2$.

Statistical analysis showed a significant difference between hardness of zirconia (group I) and hardness of PEEK (group II) $(\mathrm{t}=0.000)$.

The significant difference between microhardness of $\mathrm{Y}$ TZP and PEEK can be attributed to the difference in the natural composition of the two materials. Zirconia is a ceramic material with a relatively high hardness while PEEK is a polymer that possesses a surface that could be easily indented or abraded.

Our findings are important to be noted when planning different surface treatment methods. PEEK surface treatment is expected to be a much simpler process than the surface treatment of Y-TZP.

To the best of our knowledge no direct comparison was done between the microhardness of zirconia and PEEK

Flexural strength is a very important property for dental implant materials. One of the main issues concerning the choice of dental implant material is its modulus of elasticity. If a large difference is found between the modulus of elasticity of the material and that of its surrounding bone, stress shielding might occur leading to increased rate of peri-implant bone loss (16).

Another main concern is the effect of regular use and aging on the mechanical properties of dental implant materials. Cyclic loading is one of the main methods of mechanical aging that simulates the mechanical load present during normal masticatory function (23). By comparing the flexural strength and elastic moduli of different materials before and after cyclic loading we could have a general idea about the prognosis of different dental implant material during function.

For group I significant decrease in the flexural strength of zirconia before cyclic loading $(135.1 \pm 23.5 \mathrm{~N} / \mathrm{mm} 2)$ when compared to zirconia after cyclic loading (89.7 \pm 11.4 $\mathrm{N} / \mathrm{mm} 2) \quad(\mathrm{t}=0.000)$. Also analysis showed significant decrease in the elastic modulus of zirconia before cyclic loading (216.49 $\pm 37.7 \mathrm{GPa})$ when compared to zirconia after cyclic loading $(149.59 \pm 19.1 \mathrm{GPa})(\mathrm{t}=0.000)$.

The results obtained in the current study are comparable to the results obtained by Vagkopoulou et al (2009) (32). The authors stated that the average elastic modulus of YTZP was $201 \mathrm{GPa}$. Kohal et al (2011) (23) conducted an experiment to test the effect of cyclic loading on the strength and elastic modulus of Y-TZP. The results showed that cyclic loading significantly decreased both the elastic modulus and fracture strength of Y-TZP.

Similarly, Aboushelib et al (2016) (36) studied the effect of cyclic loading on flexural strength of zirconia. The authors concluded that cyclic loading significantly reduces the flexural strength of zirconia. 
On the other hand for group II PEEK showed no statistically significant difference in flexural strength before $(26.7 \pm 4.3 \mathrm{~N} / \mathrm{mm} 2)$ and after cyclic loading $(27.3 \pm 2.2$ $\mathrm{N} / \mathrm{mm} 2)(\mathrm{t}=0.710)$. Analysis also showed no significant difference in the elastic modulus of PEEK before cyclic loading (5.94 $\pm 0.96 \mathrm{GPa}$ ) when compared to PEEK after cyclic loading $(6.11 \pm 0.49 \mathrm{GPa})(\mathrm{t}=0.650)$.

The results of our study is comparable to the results of the test performed by Schwitalla et al (2015) (37). The authors tested the elastic modulus of different PEEK composites. The results of modulus of elasticity of PEEK Optima similar to that used in our study showed a mean of $(4.09 \pm 0.80$ GPa). Similarly Selvam (2016) (38) found that the flexural strength of PEEK was $29.56 \mathrm{~N} / \mathrm{mm} 2$ and its modulus of elasticity was $3.7 \mathrm{GPa}$.

Schambron et al (2008) (39) conducted an experiment to evaluate the effect of aging and cyclic loading on the flexural strength of carbon fiber reinforced PEEK (CF/PEEK). The results were comparable to the results obtained in our study and showed no significant change in the flexural strength of (CF/PEEK) after cyclic loading. Similarly Dworak et al (2017)(40) concluded in their experiment that cyclic loading had no significant effect on the flexural strength and elastic modulus of different PEEK composites.

Statistical analysis showed significant difference between flexural strength of zirconia before $(135.1 \pm 23.5 \mathrm{~N} / \mathrm{mm} 2)$ and after (89.7 $\pm 11.4 \mathrm{~N} / \mathrm{mm} 2)$ cyclic loading when compared to that of PEEK (26.7 $\pm 4.3 \mathrm{~N} / \mathrm{mm} 2)$, $(27.3 \pm 2.2$ $\mathrm{N} / \mathrm{mm} 2)(\mathrm{t}=0.000)$. Also there was a statistically significant difference between elastic modulus of zirconia before $(216.49 \pm 37.7 \mathrm{GPa})$ and after (149.59 $\pm 19.1 \mathrm{GPa})$ cyclic loading when compared to that of PEEK (5.94 $\pm 0.96 \mathrm{GPa})$, $(6.11 \pm 0.49 \mathrm{GPa})(\mathrm{t}=0.000)$.

From our results it could be concluded that the use of zirconia implants could lead to accelerated peri-implant bone loss due to the gradient difference between the elastic modulus of zirconia implant and surrounding bone. Also the zirconia exhibited a significant decrease in flexural strength when subjected to cyclic loading this could be explained by its ceramic nature in which continuous load could lead to crack propagation.

On the other hand PEEK shows promising results with its modulus of elasticity close to bone leading to reduced periimplant bone loss and reduced stress shielding. Also PEEK exhibited minimal fatigue when subjected to cyclic loading this is mainly due to its flexible nature as a polymer and the absence of crack propagation.

To the best of our knowledge no direct comparison was performed between zirconia and PEEK with regards to flexural strength and elastic modulus.

\section{CONCLUSION}

Within the limitations of our current study PEEK possesses superior mechanical properties when compared to zirconia as a dental implant material.

\section{CONFLICT OF INTEREST}

The authors declare that they have no conflicts of interest.

\section{REFERENCES}

1- Chappuis V, Buser R, Brägger U, Bornstein MM, Salvi GE, Buser D. Long-Term Outcomes of Dental Implants with a Titanium Plasma-Sprayed Surface: A 20-Year Prospective Case Series Study in Partially Edentulous Patients. Clin Implant Dent Relat Res. 2013;15:780-90.

2- Brånemark PI, Adell R, Breine U, Hansson BO, Lindström J, Ohlsson A. Intra-osseous anchorage of dental prostheses.

I. Experimental studies. Scand J Plast Reconstr Surg. 1969;3:81-100.

3- Velasco-Ortega E, Jos A, Cameán AM, Pato-Mourelo J, Segura-Egea JJ. In vitro evaluation of cytotoxicity and genotoxicity of a commercial titanium alloy for dental implantology. Mutat Res - Genet Toxicol Environ Mutagen. 2010;702:17-23.

4- Javed F, Al-Hezaimi K, Almas K, Romanos GE. Is Titanium Sensitivity Associated with Allergic Reactions in Patients with Dental Implants? A Systematic Review. Clin Implant Dent Relat Res. 2013;15:47-52.

5- Huiskes R, Weinans H, van Rietbergen B. The relationship between stress shielding and bone resorption around total hip stems and the effects of flexible materials. Clin Orthop Relat Res. 1992;:124-34.

6- Aydin C, Yilmaz H, Bankoğlu M. A single-tooth, two-piece zirconia implant located in the anterior maxilla: A clinical report. J Prosthet Dent. 2013;109:70-4.

7- Andreiotelli M, Wenz HJ, Kohal RJ. Are ceramic implants a viable alternative to titanium implants? A systematic literature review. Clin Oral Implants Res. 2009;20:32-47.

8- Schwitalla A, Müller W-D. PEEK dental implants: a review of the literature. J Oral Implantol. 2013;39:743-9.

9- Depprich R, Naujoks C, Ommerborn M, Schwarz F, Kübler NR, Handschel J. Current findings regarding zirconia implants. Clin Implant Dent Relat Res. 2014;16:124-37.

10-Kohal RJ, Klaus G, Strub JR. Zirconia-implant-supported all-ceramic crowns withstand long-term load: A pilot investigation. Clin Oral Implants Res. 2006;17:565-71.

11-Lucas TJ, Lawson NC, Janowski GM, Burgess JO. Effect of grain size on the monoclinic transformation, hardness, roughness, and modulus of aged partially stabilized zirconia. Dent Mater. 2015;31:1487-92.

12-van Steenberghe D, Quirynen M, Naert I, Maffei G, Jacobs R. Marginal bone loss around implants retaining hinging mandibular overdentures, at 4-, 8- and 12-years follow-up. J Clin Periodontol. 2001;28:628-33.

13-Moon SM, Ingalhalikar A, Highsmith JM, Vaccaro AR. Biomechanical rigidity of an all-polyetheretherketone anterior thoracolumbar spinal reconstruction construct: an in vitro corpectomy model. Spine J. Elsevier Inc; 2009;9:330-5.

14-Skinner H. Composite Technology for Total Hip Arthroplasty. Clin Orthop Relat Res. 1988;235:224-36.

15-Barkarmo S, Wennerberg A, Hoffman M, Kjellin P, Breding K, Handa P, et al. Nano-hydroxyapatite-coated PEEK implants: A pilot study in rabbit bone. J Biomed Mater Res - Part A. 2013;101 A:465-71. 
16-Lee WT, Koak JY, Lim YJ, Kim SK, Kwon HB, Kim MJ. Stress shielding and fatigue limits of poly-ether-etherketone dental implants. J Biomed Mater Res - Part B Appl Biomater. 2012;100 B:1044-52.

17-Kurtz SM, Devine JN. PEEK biomaterials in trauma, orthopedic, and spinal implants. Biomaterials. 2007. p. 4845-69.

18-Specimens P, Materials EI. Standard Test Methods for Flexural Properties of Unreinforced and Reinforced Plastics and Electrical Insulating Materials 1. 2010:1-11.

19-Ewais OH, Al Abbassy F, Ghoneim MM, Aboushelib MN. Novel zirconia surface treatments for enhanced osseointegration: Laboratory characterization. Int J Dent. 2014;2014.

20-Schatz C, Strickstrock M, Roos M, Edelhoff D, Eichberger $\mathrm{M}$, Zylla IM, et al. Influence of specimen preparation and test methods on the flexural strength results of monolithic zirconia materials. Materials. 2016;9:1-13.

21-C1161-13 A. Standard Test Method for Flexural Strength of Advanced Ceramics at Ambient. Annu B ASTM Stand. 2008;94:1-16.

22-Goyal RK, Tiwari AN, Negi YS. Microhardness of PEEK / ceramic micro- and nanocomposites: Correlation with Halpin - Tsai model. Mater Sci Eng A. 2008;491:230-6.

23-Kohal RJ, Wolkewitz M, Tsakona A. The effects of cyclic loading and preparation on the fracture strength of zirconium-dioxide implants: An in vitro investigation. Clin Oral Implants Res. 2011;22:808-14.

24-Kirkpatrick LA, Feeney BC. A simple guide to IBM SPSS: for version 20.0. Nelson Education; 2012.

25-Najeeb S, BDS ZK, BDS SZ, BDS MSZ. Bioactivity and Osseointegration of PEEK Are Inferior to Those of Titanium: A Systematic Review. J Oral Implantol. 2016;42:512-6.

26-Velasco-Ortega E, Jos A, Cameán AM, Pato-Mourelo J, Segura-Egea JJ. In vitro evaluation of cytotoxicity and genotoxicity of a commercial titanium alloy for dental implantology. Mutat Res - Genet Toxicol Environ Mutagen. Elsevier B.V.; 2010;702:17-2

27-Camarini ET, Tomeh JK, Dias RR, da Silva EJ. Reconstruction of Frontal Bone Using Specific Implant Polyether-Ether-Ketone. J Craniofac Surg. 2011;22:22057.

28-Stawarczyk B, Eichberger M, Uhrenbacher J, Wimmer T, Edelhoff D, Schmidlin PR. Three-unit reinforced polyetheretherketone composite FDPs: Influence of fabrication method on load-bearing capacity and failure types. Dental materials journal. 2015 Jan 30;34:7-12.

29-Salihoglu Yener E, Ozcan M, Kazazoglu E. A comparative study of biaxial flexural strength and Vickers microhardness of different zirconia materials: Effect of glazing and thermal cycling. Brazilian Dent Sci. 2015;18:19.

30-Panayotov IV, Orti V, Cuisinier F, Yachouh J. Polyetheretherketone (PEEK) for medical applications. J Mater Sci Mater Med. 2016;27.

31-Pittayachawan P, McDonald A, Petrie A, Knowles JC. The biaxial flexural strength and fatigue property of LavaTM YTZP dental ceramic. Dent Mater. 2007;23:1018-29.
32-Vagkopoulou T, Koutayas SO, Koidis P, Strub JR. Zirconia in dentistry: Part 1. Discovering the nature of an upcoming bioceramic. Eur J Esthet Dent. 2009;4:130-51.

33-Murali Ramamoorthi, Vivek Verma ZS. Dental biomaterials and a novel composite of Zirconia and Poly Ether Ether Ketone [ PEEK ] for dental implants Dental biomaterials and a novel composite of Zirconia and Poly Ether Ether Ketone [ PEEK ] for dental implants. 2015;2:16-22.

34-Goyal RK, Tiwari AN, Negi YS. Microhardness of PEEK / ceramic micro- and nanocomposites: Correlation with Halpin - Tsai model. 2008;491:230-6.

35-Wang L, Weng L, Wu Z, Wang C. The Properties of Polyetheretherketone Biocomposite Reinforced By. 2015;1096:214-8.

36-Aboushelib MN, Wang H, Kleverlaan CJ, Feilzer AJ. Fatigue behavior of zirconia under different loading conditions. Dent Mater. The Academy of Dental Materials; 2016;32:915-20.

37-Schwitalla AD, Spintig T, Kallage I, Müller WD. Flexural behavior of PEEK materials for dental application. Dent Mater. The Academy of Dental Materials; 2015;31:137784.

38-Selvam S. Development and Investigation of Mechanical Properties of PEEK Fine Particles Reinforced UHMWPE Composites. 2016;11:1298-303.

39-Schambron T, Lowe A, McGregor $\mathrm{H}$ V. Effects of environmental ageing on the static and cyclic bending properties of braided carbon fibre/PEEK bone plates. Compos Part B Eng. 2008;39:1216-20.

40-Dworak M, Rudawski A, Markowski J, Blazewicz S. Dynamic mechanical properties of carbon fibre-reinforced PEEK composites in simulated body-fluid. Compos Struct. Elsevier Ltd; 2017;161:428-34. 